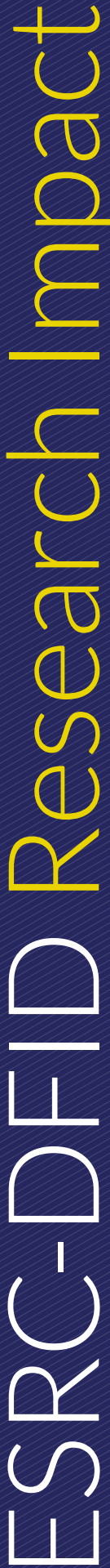

\title{
MOTHER TONGUE EDUCATION IMPROVES LITERACY IN UGANDA
}

Children whose first language is not the language of instruction in school are more likely to drop out or fail in early grades. Research from the Universities of Illinois and their Ugandan partners Mango Tree Educational Enterprises and the Ichuli Institute, Kampala, demonstrates that the provision of teacher support and educational resources produced in local languages can lead to large learning gains in rural, under-resourced and overcrowded classrooms.

\section{THE CHALLENGE}

In Uganda, as in many other countries in sub-Saharan Africa, access to primary school has expanded rapidly over recent decades. However, these gains have not been matched by improvements in learning, especially in literacy. In the Lango region of northern Uganda, 80 per cent of children aged 7-8 years are unable to read. Previous research has shown that a child's first language is preferable for literacy and learning throughout primary school. Children who receive mother tongue-based multilingual education also perform better in their second language. However, in the Lango region, reading is usually taught in English, and not in the local language, Leblango.

National efforts to promote mother tongue education policies have been largely unsuccessful due to underdeveloped rules for the writing and spelling of local words, a lack of education materials produced in local languages, and the absence of quality training to support teachers to deliver local-language curriculums.

\section{THE RESEARCH}

Funded through the ESRC-DFID Raising Learning Outcomes in Education Systems Research Programme, the aim of the research was to evaluate and measure

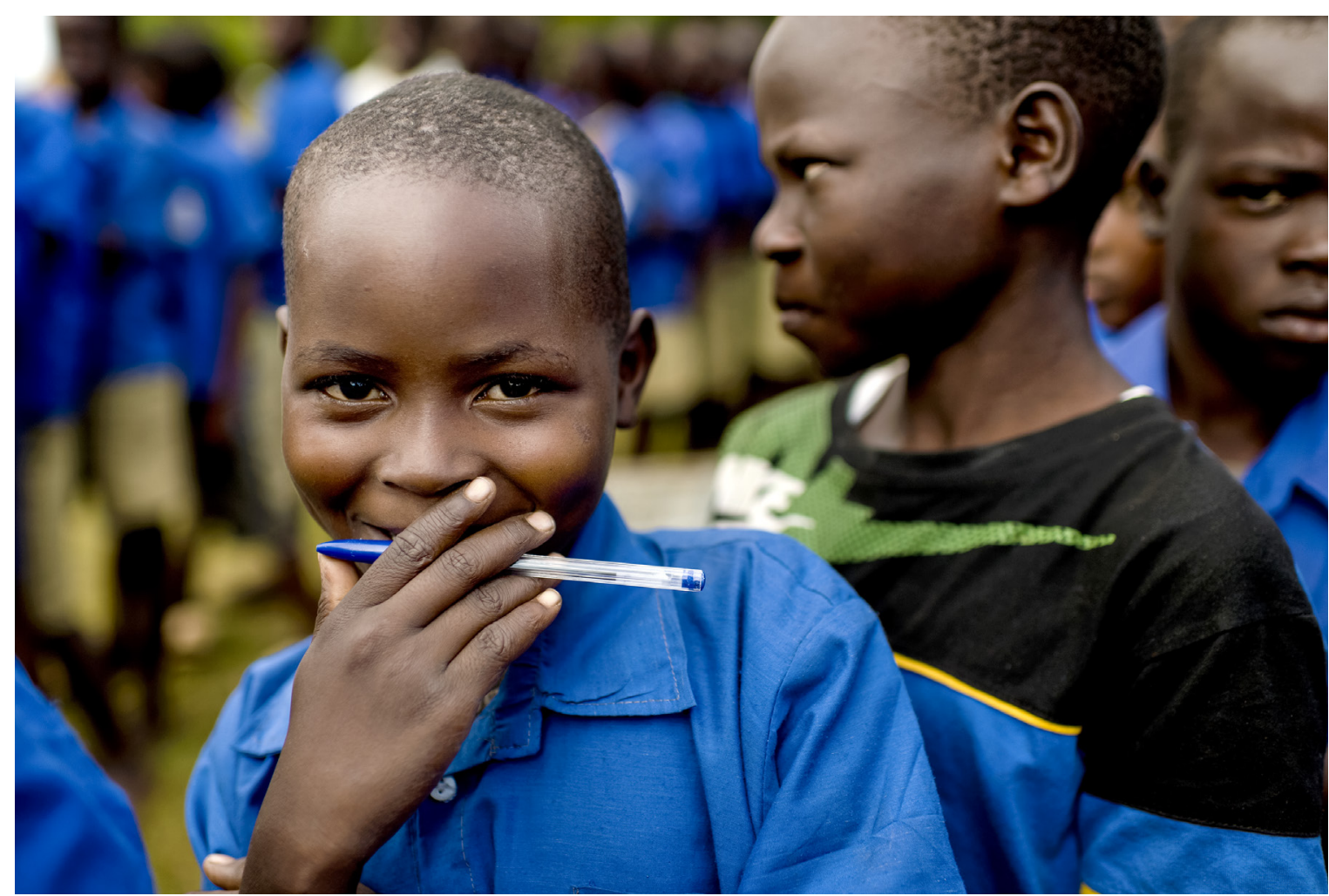

Cover photo: Tororo, Uganda: A boy giggles during a presentation on menstrual hygiene management at Agwait Primary School. Credit: Nyani Quarmyne/Panos. 
the effectiveness of the innovative Mango Tree Literacy Programme in Uganda which seeks to emphasise mother tongue literacy education.

The programme engages indigenous writers, artists, designers and technical experts, as well as teachers, to co-develop education materials in local languages. Teacher training has an explicit focus on improving written and spoken language skills, and parents are taught how to interpret their child's literacy report card and use the results to support learning at home.

A randomised control trial of the programme took place in 128 schools in the Lango region over four years (2013-17). The researchers found that Mango Tree's approach succeeded in substantially improving literacy levels in early primary school grades, raising literacy levels equivalent to a whole additional year of schooling - amongst the largest improvements ever achieved for randomised education interventions of this kind.

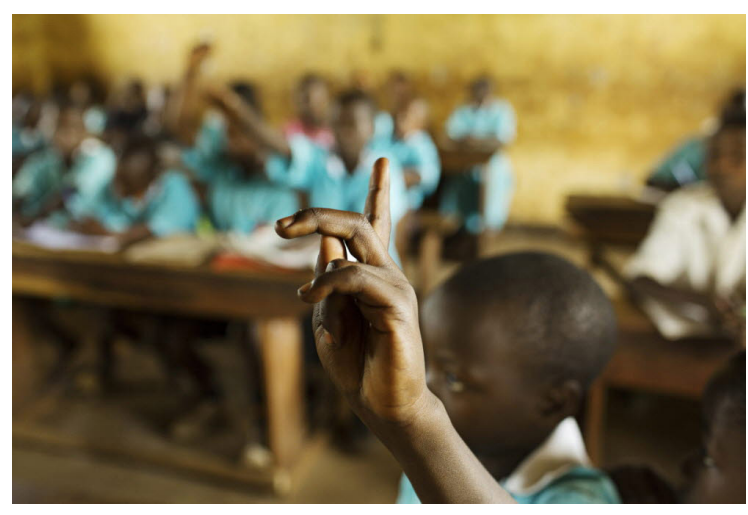

Uganda Kampangi, Rakai. A pupil holds up their hand to ask a question at St. Henry's school where about 410 students between the ages of 6 and 16 are enrolled. Credit: Mikkel Ostergaard / Panos.

\section{THE IMPACT}

Results from the research have reinforced the benefits of Mango Tree's approach to literacy instruction.

Thanks to Mango Tree's role in the research process, a project team member is part of a national literacy technical working group advising the government on successful approaches to improving literacy instruction and teacher training and support.
The research findings have also influenced a United States Agency for International Development (USAID) White Paper on approaches to improving literacy instruction in Uganda. Heidi Soule, USAID Uganda Education, Youth and Child Development Advisor reported that 'Without this research, the local language development component would not have been included in the White Paper.' The paper will be incorporated into a national reflection and dialogue about the future of literacy programming at an upcoming USAID-sponsored National Reading Symposium where participants, including prominent Ministry of Education officials, parliamentarians, practitioners, and non-governmental organisation leaders will vote on priorities for future national education programming in Uganda.

Not only has the project stimulated a passion for local language literacy and a love for reading in local language in homes, communities, and schools, but the impact of the research has contributed to knowledge about successful approaches to teacher training and effective instructional materials in Uganda, which have the potential to transform learning in all low-income contexts.

\section{FURTHER READING}

Kerwin, Jason and Thornton, Rebecca L., Making the Grade: The Sensitivity of Education Program Effectiveness to Input Choices and Outcome Measures (January 30, 2018). Available at SSRN: https://ssrn.com/abstract $=3002723$ or http://dx.doi.org/10.2139/ssrn.3002723

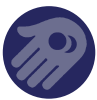

The Literacy Laboratory Project (LLP) under the Northern Uganda Literacy Program

The research team was funded by ESRC-DFID's Raising Learning Outcomes in Education Systems Research Programme, led by Rebecca Thornton, Department of Economics, University of Illinois. The research was carried out in partnership with the University of Minnesota, the University of Wisconsin, the Copenhagen Business School, Mango Tree Educational Enterprises, and the Ichuli Institute.

\section{THE IMPACT INITIATIVE}

\section{For International Development Research}

The Impact Initiative seeks to connect policymakers and practitioners with the world-class social science research supported by the ESRC-DFID Strategic Partnership, maximising the uptake and impact of research from: (i) the Joint Fund for Poverty Alleviation Research, and (ii) the Raising Learning Outcomes in Education Systems Programme. We seek to identify synergies between these programmes and their grant holders, support them to exploit influencing and engagement opportunities, and facilitate mutual learning. The Impact Initiative is a collaboration between the Institute of Development Studies (IDS) and the University of Cambridge's Research for Equitable Access and Learning (REAL) Centre.

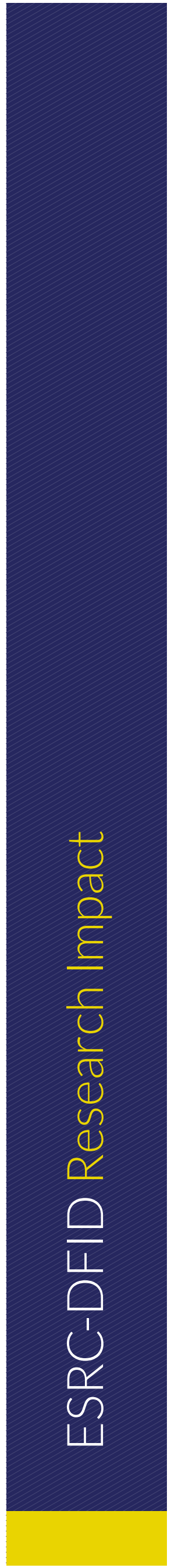

